\title{
Circumstances of witnessed drug overdose in New York City: implications for intervention
}

\author{
Melissa Tracy ${ }^{\mathrm{a}}$, Tinka Markham Piper ${ }^{\mathrm{a}}$, Danielle Ompad ${ }^{\mathrm{a}}$, Angela Bucciarelli ${ }^{\mathrm{a}}$, \\ Phillip O. Coffin ${ }^{\text {a }}$, David Vlahov ${ }^{\text {a, b }}$, Sandro Galea ${ }^{\mathrm{a}, \mathrm{b}, *}$ \\ ${ }^{a}$ Center for Urban Epidemiologic Studies, New York Academy of Medicine, 1216 Fifth Avenue, New York, NY 10029, USA \\ ${ }^{\mathrm{b}}$ Department of Epidemiology, Columbia University Mailman School of Public Health, New York, NY 10032, USA
}

Received 31 August 2004; received in revised form 7 January 2005; accepted 26 January 2005

\begin{abstract}
Drug users frequently witness the nonfatal and fatal drug overdoses of their peers, but often fail to intervene effectively to reduce morbidity and mortality. We assessed the circumstances of witnessed heroin-related overdoses in New York City (NYC) among a predominantly minority population of drug users. Among 1184 heroin, crack, and cocaine users interviewed between November 2001 and February 2004,672 (56.8\%) had witnessed at least one nonfatal or fatal heroin-related overdose. Of those, $444(67.7 \%)$ reported that they or someone else present called for medical help for the overdose victim at the last witnessed overdose. In multivariable models, the respondent never having had an overdose her/himself and the witnessed overdose occurring in a public place were associated with the likelihood of calling for medical help. Fear of police response was the most commonly cited reason for not calling or delaying before calling for help (52.2\%). Attempts to revive the overdose victim through physical stimulation (e.g., applying ice, causing pain) were reported by $59.7 \%$ of respondents, while first aid measures were attempted in only $11.9 \%$ of events. Efforts to equip drug users to manage overdoses effectively, including training in first aid and the provision of naloxone, and the reduction of police involvement at overdose events may have a substantial impact on overdose-related morbidity and mortality.
\end{abstract}

(C) 2005 Elsevier Ireland Ltd. All rights reserved.

Keywords: Overdose; Heroin; Drug use; Emergency medical services

\section{Introduction}

Approximately half of all illicit drug users report at least one nonfatal overdose during their lifetime (Seal et al., 2001; Ochoa et al., 2001; Davidson et al., 2002), and death rates from accidental drug overdose have been increasing throughout the United States over the past decade (CDC, 2000a, 2000b, 2004). In New York City (NYC), deaths due to drug abuse currently rank among the five leading causes of death in 15-54 year olds (NYC DOHMH, 2003), and drug-related hospitalization accounted for up to $9.0 \%$ of all hospital admissions in 2001 in some neighborhoods (Karpati et al., 2003a, 2003b). Complications of drug overdose include pulmonary edema, cardiac arrhythmia, rhabdomyolysis, cognitive im-

\footnotetext{
* Corresponding author. Tel.: +1 212822 7378; fax: +1 2128766220

E-mail address: sgalea@nyam.org (S. Galea).
}

pairment, and indirect physical injury resulting from unintentional falls and burns (Sporer, 1999; Darke et al., 2000; Warner-Smith et al., 2001, 2002).

Drug users rarely overdose while alone (Darke and Hall, 2003; Sergeev et al., 2003; Powis et al., 1999; Darke et al., 1996a), and death from drug overdose is rarely instantaneous (Zador et al., 1996; Darke and Zador, 1996), creating opportunities for those present to reduce potential morbidity and mortality through timely intervention. More than $90 \%$ of heroin overdose victims who receive emergency medical care while still exhibiting pulse and blood pressure survive (Sporer et al., 1996), although neurological and other physical effects of overdose become more severe if hypoxia is prolonged (Darke et al., 1996b, 2000; Warner-Smith et al., 2001) affirming the importance of seeking medical attention as quickly as possible during overdose events. It has been estimated that only between $10 \%$ and $56 \%$ of individuals who 
witness a drug overdose call for emergency medical services, with most of those doing so only after other attempts to revive the overdose victim (e.g., inflicting pain or applying ice) have proved unsuccessful (Davidson et al., 2002; Zador et al., 1996; Darke et al., 1996b; McGregor et al., 1998). Few studies have assessed responses to witnessed overdoses among minority populations, although these populations suffer disproportionately from the consequences of drug use in many cities (Galea et al., 2003a; Davidson et al., 2003; Galea and Vlahov, 2002). Also, differences in seeking help for overdose victims may exist between racial/ethnic groups (Davidson et al., 2002; Galea et al., 2003a). Understanding the factors associated with appropriate responses during witnessed overdose events among minority populations may help to eliminate barriers to obtaining emergency medical care for overdose victims and reduce overdose-related morbidity and mortality (Darke and Hall, 2003; Davidson et al., 2002; Ochoa et al., 2001; Darke et al., 1996b).

We assessed the circumstances of witnessed nonfatal and fatal heroin-related overdoses in NYC to determine the responses to overdose common among a predominantly minority urban population of illicit drug users. We sought to identify predictors of and barriers to seeking medical help during witnessed overdose events, in order to inform interventions aimed at reducing the consequences of drug overdose.

\section{Methods}

\subsection{Participants and measures}

Recruitment, involving targeted sampling with street outreach techniques, was carried out by trained outreach workers in Central Harlem and the South Bronx in NYC from November 2001 through February 2004. Recruitment methods used in this study have been described in more detail elsewhere (Diaz et al., 2001a, 2001b; Ompad et al., in press). Eligibility requirements included being 18 years of age or older and having used heroin, crack, or cocaine at least once in the 2 months prior to the interview. Questionnaires were administered in English or Spanish by trained interviewers, assessing demographic characteristics, drug use behaviors, and overdose experience.

"Overdose" was defined as "someone who collapses, has blue skin color, convulsions, difficulty breathing, loses consciousness, cannot be woken up, or has a heart attack or dies while using drugs." We asked respondents if they had ever overdosed; those who had were asked how many times they had overdosed in the past 6 months, in the past year, and in their lifetime. They were also asked to provide detailed information about their most recent overdose experience, including the drugs they were using, whether others were present, if they received any medical attention, and if they had recently been in prison or drug treatment before the overdose. We also asked participants if they had ever seen someone else overdose; those who had were asked how many times they had seen an overdose in the past 6 months and in their lifetime. They were also asked to describe the circumstances of the overdose they had seen most recently, including their relationship to the person who overdosed, the drugs that person was using at the time of the overdose, and if the person lived or died. This analysis is limited to witnessed overdose events in which heroin was reported to have been used, either alone or in combination with other drugs, in order to facilitate comparisons with other studies. In addition, witnesses were asked if they or anyone else present had sought outside medical help for the overdose victim and were subsequently asked to enumerate the actions taken during the overdose event. Participants who responded "yes" to the question "did you or others there get or call for outside medical help?" or who reported that someone present called an ambulance, took the overdose victim to the hospital, or went for help from others during the last witnessed overdose were considered to have "called for medical help" in the following analysis. Respondents who had ever seen someone overdose were also asked if they had hesitated before getting or calling for medical help at the last witnessed event; those who reported delaying or not calling for help were asked to list the reasons why they had delayed or failed to get help. Finally, we asked respondents if they had ever personally known anyone who died of a drug overdose.

\subsection{Analyses}

We calculated the prevalence of ever witnessing a nonfatal or fatal drug overdose and, restricting the sample to respondents whose most recently witnessed overdose involved heroin, we described the demographic and drug use characteristics of the witnesses as well as circumstances of the last heroin-related witnessed overdose event. We used two-tailed $\chi^{2}$-tests to assess the relations between characteristics of the witness and of the witnessed overdose event and the likelihood that those present called for medical help for the overdose victim. All characteristics that were associated $(p<0.2)$ with calling for medical help at the last witnessed overdose were included in a multivariable model. We also restricted the sample to witnesses who had ever overdosed themselves and created a second multivariable model in order to assess the specific characteristics of one's prior overdose history that may influence responses to witnessed overdose. Finally, we described the actions taken by those present at the last heroin-related witnessed overdose and the reasons reported for delaying or not getting help.

\section{Results}

\subsection{Prevalence of witnessed overdose}

Of 1184 participants recruited to the study, 797 (67.3\%) reported ever having witnessed a nonfatal or fatal drug overdose. Of these, 278 (35.2\%) had seen an overdose in the past 6 months. The median number of overdoses witnessed dur- 
ing respondents' lifetime was five, while the mean number of overdoses witnessed was 11.8. Respondents who had seen an overdose were more likely than those who had never seen an overdose to have ever been in jail $(86.9 \%$ versus $78.5 \%$; $p<0.001)$, to be current injectors $(61.7 \%$ versus $50.0 \%$; $p<0.001)$, to have ever been in drug treatment $(92.5 \%$ versus $85.0 \% ; p<0.001)$, and to have ever overdosed $(44.7 \%$ versus $19.4 \%$; $p<0.001)$. Of the 797 respondents who had ever seen someone else overdose, $672(84.3 \%)$ reported that heroin was being used by the overdose victim at the most recently witnessed overdose event. An average of 4.3 years (S.D. 7.2 years; median 1 year; range $<1-44$ years) had passed between the last witnessed overdose and the interview among these respondents. The most recently witnessed heroin-related overdose reportedly ended in death in 132 (21.2\%) cases.

\subsection{Characteristics of witnesses and last witnessed overdose}

Table 1 summarizes the demographic characteristics and overdose experience of respondents who had witnessed a heroin-related overdose, as well as the circumstances of the last witnessed overdose. The majority of witnesses had injected drugs in the previous 2 months $(64.3 \%)$ and had been using drugs for over 20 years $(52.7 \%)$ at the time of the interview. About a quarter $(25.7 \%)$ of the witnesses had seen more than 10 overdoses in their lifetime and $302(45.0 \%)$ had ever experienced a nonfatal drug overdose themselves. Over half $(56.8 \%)$ of those who had overdosed had been taken to the hospital during their last overdose. A plurality of witnessed overdoses took place in residential settings $(35.8 \%)$, $25.0 \%$ occurred in public areas like bars, restaurants, and on the street, and $19.2 \%$ of events occurred in shooting galleries. In addition to heroin, cocaine or crack was reportedly being used by the overdose victim in $34.7 \%$ of events, while alcohol was used in $7.5 \%$ of events.

\subsection{Predictors of calling for help at last witnessed overdose}

During the most recently witnessed heroin-related overdose, $444(67.7 \%)$ respondents reported that they or someone else present called for medical help for the overdose victim. Table 1 shows the bivariate associations between characteristics of the witness and of the witnessed event and the likelihood that someone present called for medical help for the overdose victim. Covariates associated with whether someone present had called for help during the last witnessed overdose event were the respondent's history of methadone treatment $(p=0.03)$ and the location of the witnessed overdose event $(p<0.001)$. Additionally, respondents who had ever overdosed themselves were less likely to call for medical help than those with no history of prior overdose $(59.1 \%$ versus $74.9 \%$; $p<0.001$ ); however, among those who had overdosed themselves, those who had been taken to the hospital at their own last overdose were more likely to call for help during the last witnessed overdose than those who had not been taken to the hospital $(72.6 \%$ versus $41.9 \%$; $p<0.001)$. Among witnessed events at which medical help was called, witnesses to incidents occurring in public places were more likely to report being of no relation to the victim than in incidents occurring in other private locations $(41.2 \%$ versus $16.5 \% ; p<0.001$; data not shown).

Table 2 shows the unadjusted and adjusted relations between characteristics of the witness and of the witnessed overdose event and the likelihood that those present called for medical help for the overdose victim. In the first adjusted model, which includes all respondents who had most recently witnessed a heroin-related overdose $(N=652)$, medical help was more likely to have been called for the overdose victim if the overdose occurred in a public place $(\mathrm{OR}=2.20$ versus overdoses occurring in residential settings; $95 \% \mathrm{CI}=1.35-3.58$ ) but was less likely to have been called if the respondent had ever overdosed $(\mathrm{OR}=0.56$ versus never overdosed; 95\% CI =0.39-0.80), after controlling for other characteristics of the witness and of the witnessed overdose event. In the second multivariable model, which includes only those witnesses to heroin-related overdoses who had ever overdosed themselves $(N=291)$, the only significant predictor of calling for medical help was having been taken to the hospital during one's own last overdose $(\mathrm{OR}=3.18$ versus having not been taken to the hospital; 95\% $\mathrm{CI}=1.44-6.99)$.

\subsection{Actions taken at last witnessed overdose}

Table 3 lists the actions that witnesses reported were taken by those present during the most recently witnessed overdose. Overall, an ambulance was called in $40.0 \%$ of witnessed overdose events, while attempts to revive the overdose victim through physical stimulation, including applying ice and causing pain, were made in $59.7 \%$ of incidents. First aid measures, such as cardiopulmonary resuscitation (CPR) and placing the overdose victim in the coma position, were attempted in only $11.9 \%$ of cases, while those present left or did nothing for the overdose victim in $14.1 \%$ of events. Witnesses who did not call for medical help for the overdose victim were more likely than those who did call for help to attempt to stimulate the victim by applying ice, walking the victim around, injecting the victim with water, salt, or bleach, or causing pain $(79.3 \%$ versus $50.5 \% ; p<0.001)$, and were less likely to attempt first aid (7.6\% versus $14.4 \%$; $p=0.012$ ).

\subsection{Reasons for not calling or delaying before calling for help at last witnessed overdose}

Table 4 shows the reasons reported by witnesses for not seeking or delaying before seeking medical help during the last witnessed overdose. The most commonly cited reason for delaying or failing to get help was fear of police response $(52.2 \%)$. Among those who called for medical help at the last witnessed overdose, $21.2 \%$ delayed before calling for help; 
Table 1

Bivariate associations between characteristics of witnesses and of witnessed heroin-related overdose events and the likelihood that someone present called for medical help during the last witnessed overdose

\begin{tabular}{|c|c|c|c|c|c|}
\hline & \multicolumn{2}{|c|}{ Total } & \multicolumn{3}{|c|}{ Called for medical help for victim } \\
\hline & $N$ & $\%$ & $N$ called & $\%$ called & $p$-value \\
\hline Total witnesses to overdose & 672 & 100.0 & 444 & 67.7 & \\
\hline \multicolumn{6}{|l|}{ Demographic characteristics of witnesses } \\
\hline \multicolumn{6}{|l|}{ Age } \\
\hline $18-24$ & 41 & 6.1 & 24 & 60.0 & 0.58 \\
\hline $25-34$ & 198 & 29.5 & 137 & 70.3 & \\
\hline $35-44$ & 276 & 41.1 & 185 & 69.0 & \\
\hline $45-54$ & 144 & 21.4 & 90 & 64.3 & \\
\hline $55-64$ & 13 & 1.9 & 8 & 61.5 & \\
\hline \multicolumn{6}{|l|}{ Gender } \\
\hline Female & 157 & 23.5 & 108 & 70.6 & 0.37 \\
\hline Male & 511 & 76.5 & 333 & 66.7 & \\
\hline \multicolumn{6}{|l|}{ Race/ethnicity } \\
\hline White or other race & 88 & 13.1 & 56 & 63.6 & 0.60 \\
\hline Black & 167 & 24.9 & 106 & 66.7 & \\
\hline Hispanic & 417 & 62.1 & 282 & 69.0 & \\
\hline \multicolumn{6}{|l|}{ Educational attainment } \\
\hline$<$ High school & 322 & 48.1 & 223 & 70.6 & 0.13 \\
\hline High school/equivalent or higher & 347 & 51.9 & 219 & 65.0 & \\
\hline \multicolumn{6}{|l|}{ Marital status } \\
\hline Never married & 402 & 59.9 & 276 & 69.9 & 0.19 \\
\hline Married & 95 & 14.2 & 63 & 69.2 & \\
\hline Separated/widowed/divorced & 174 & 25.9 & 105 & 62.1 & \\
\hline \multicolumn{6}{|l|}{ Ever homeless } \\
\hline No & 86 & 12.8 & 56 & 65.1 & 0.59 \\
\hline Yes & 586 & 87.2 & 388 & 68.1 & \\
\hline \multicolumn{6}{|l|}{ Ever arrested } \\
\hline No & 51 & 7.6 & 35 & 71.4 & 0.56 \\
\hline Yes & 621 & 92.4 & 409 & 67.4 & \\
\hline \multicolumn{6}{|l|}{ Ever in jail } \\
\hline No & 76 & 11.9 & 50 & 68.5 & 0.80 \\
\hline Yes & 564 & 88.1 & 370 & 67.0 & \\
\hline \multicolumn{6}{|l|}{ Injector status } \\
\hline Never & 81 & 12.2 & 62 & 77.5 & 0.06 \\
\hline Former & 156 & 23.5 & 103 & 70.1 & \\
\hline Current & 427 & 64.3 & 272 & 64.6 & \\
\hline \multicolumn{6}{|l|}{ Length of drug-using career } \\
\hline$<1-10$ years & 72 & 10.8 & 48 & 67.6 & 0.67 \\
\hline $11-15$ years & 99 & 14.8 & 72 & 72.7 & \\
\hline $16-20$ years & 146 & 21.8 & 94 & 65.3 & \\
\hline $21+$ years & 353 & 52.7 & 230 & 67.3 & \\
\hline \multicolumn{6}{|l|}{ Ever in methadone treatment } \\
\hline No & 203 & 30.2 & 145 & 73.6 & 0.03 \\
\hline Yes & 469 & 69.8 & 299 & 65.1 & \\
\hline \multicolumn{6}{|c|}{ Ever in detox or other type of drug treatment } \\
\hline No & 114 & 17.0 & 74 & 66.7 & 0.80 \\
\hline Yes & 558 & 83.0 & 370 & 67.9 & \\
\hline \multicolumn{6}{|c|}{ Any risky injection practices at last injection ${ }^{\mathrm{a}}$} \\
\hline No & 278 & 53.0 & 183 & 66.6 & 0.57 \\
\hline Yes & 247 & 47.1 & 152 & 64.1 & \\
\hline \multicolumn{6}{|c|}{ Characteristics of witnessed overdose events } \\
\hline \multicolumn{6}{|c|}{ Relationship of overdose victim to witness } \\
\hline No relation & 167 & 25.0 & 106 & 68.4 & 0.97 \\
\hline
\end{tabular}


Table 1 (Continued)

\begin{tabular}{|c|c|c|c|c|c|}
\hline & \multicolumn{2}{|l|}{ Total } & \multicolumn{3}{|c|}{ Called for medical help for victim } \\
\hline & $N$ & $\%$ & $N$ called & $\%$ called & $p$-value \\
\hline Fellow drug user & 55 & 8.2 & 36 & 66.7 & \\
\hline Friend/family member/sexual partner & 447 & 66.8 & 302 & 67.9 & \\
\hline \multicolumn{6}{|l|}{ Location of witnessed overdose } \\
\hline Home & 239 & 35.8 & 150 & 63.8 & $<0.001$ \\
\hline Shooting gallery & 128 & 19.2 & 75 & 61.5 & \\
\hline Abandoned building/SRO/hotel room & 51 & 7.7 & 28 & 57.1 & \\
\hline Public place ${ }^{b}$ & 167 & 25.0 & 131 & 79.9 & \\
\hline Other ${ }^{\mathrm{c}}$ & 82 & 12.3 & 56 & 68.3 & \\
\hline \multicolumn{6}{|l|}{ OD victim was using cocaine or crack } \\
\hline No & 439 & 65.3 & 292 & 68.2 & 0.68 \\
\hline Yes & 233 & 34.7 & 152 & 66.7 & \\
\hline \multicolumn{6}{|l|}{ OD victim was using alcohol } \\
\hline No & 614 & 92.5 & 409 & 68.1 & 0.43 \\
\hline Yes & 50 & 7.5 & 30 & 62.5 & \\
\hline \multicolumn{6}{|c|}{ OD victim was using tranquilizers/barbs/benzos } \\
\hline No & 643 & 96.8 & 424 & 67.5 & 0.71 \\
\hline Yes & 21 & 3.2 & 15 & 71.4 & \\
\hline \multicolumn{6}{|l|}{ OD victim was using other drug(s) } \\
\hline No & 583 & 86.8 & 386 & 68.0 & 0.70 \\
\hline Yes & 89 & 13.2 & 58 & 65.9 & \\
\hline \multicolumn{6}{|l|}{ OD victim was using more than one drug } \\
\hline No & 388 & 57.7 & 254 & 67.2 & 0.76 \\
\hline Yes & 284 & 42.3 & 190 & 68.4 & \\
\hline \multicolumn{6}{|l|}{ Overdose experience of witnesses } \\
\hline \multicolumn{6}{|l|}{ Number of overdoses witnessed in lifetime } \\
\hline $1-2$ & 181 & 26.9 & 128 & 72.7 & 0.12 \\
\hline $3-5$ & 174 & 25.9 & 120 & 70.2 & \\
\hline $6-10$ & 144 & 21.4 & 93 & 66.0 & \\
\hline $11+$ & 173 & 25.7 & 103 & 61.3 & \\
\hline \multicolumn{6}{|c|}{ Ever personally known anyone who died of an OD } \\
\hline No & 187 & 28.5 & 127 & 69.8 & 0.38 \\
\hline Yes & 470 & 71.5 & 305 & 66.2 & \\
\hline \multicolumn{6}{|l|}{ Ever overdosed } \\
\hline No & 369 & 55.0 & 269 & 74.9 & $<0.001$ \\
\hline Yes & 302 & 45.0 & 175 & 59.1 & \\
\hline \multicolumn{6}{|l|}{ Someone called 911 at own last OD } \\
\hline No & 146 & 49.0 & 64 & 45.4 & $<0.001$ \\
\hline Yes & 152 & 51.0 & 108 & 71.5 & \\
\hline \multicolumn{6}{|l|}{ Taken to hospital at own last OD } \\
\hline No & 131 & 43.2 & 54 & 41.9 & $<0.001$ \\
\hline Yes & 172 & 56.8 & 122 & 72.6 & \\
\hline
\end{tabular}

${ }^{a}$ Risky injection practices include splitting drug with needle and sharing cooker, cotton, rinse water, or needle.

b Public place includes street, schoolyard, parking lot or other open area, bar, restaurant, store or other public building.

c Other location includes car, jail, or "other".

the most frequently reported reason for the delay was fear of police response $(66.3 \%)$. Among those who did not call for medical help, $46.2 \%$ reported fear of police response as a reason for not getting help, while $36.3 \%$ did not get help because they thought they could handle the overdose event themselves. Of those who cited a belief in their ability to handle the event without aid as a reason for not getting help, only $1(1.3 \%)$ reported a fatal outcome for the witnessed overdose, significantly less than the $11.3 \%$ of outcomes reported to be fatal by respondents who did not call for help due to other reasons ( $p=0.009$; data not shown).

\section{Discussion}

In a study of 1184 drug users, we found that a substantial proportion had witnessed at least one overdose in their lifetime, with the majority of most recently witnessed incidents 
Table 2

Unadjusted and adjusted relations between characteristics of witnesses and of witnessed heroin-related overdose events and the likelihood that someone present called for medical help during the last witnessed overdose

\begin{tabular}{|c|c|c|c|c|c|c|}
\hline & \multicolumn{2}{|c|}{$\begin{array}{l}\text { Unadjusted } \\
(N=672)\end{array}$} & \multicolumn{2}{|c|}{$\begin{array}{l}\text { Adjusted Model I including } \\
\text { all witnesses }(N=652)^{\dagger}\end{array}$} & \multicolumn{2}{|c|}{$\begin{array}{l}\text { Adjusted Model II including witnesses } \\
\text { who ever overdosed }(N=291)^{\mathrm{a}}\end{array}$} \\
\hline & OR & $95 \% \mathrm{CI}$ & OR & $95 \% \mathrm{CI}$ & OR & $95 \% \mathrm{CI}$ \\
\hline \multicolumn{7}{|l|}{ Demographic characteristics of witnesses } \\
\hline \multicolumn{7}{|l|}{ Educational attainment } \\
\hline$<$ High school & 1.00 & - & 1.00 & - & 1.00 & - \\
\hline High school/equivalent or higher & 0.77 & $0.56-1.08$ & 0.93 & $0.66-1.32$ & 0.93 & $0.55-1.58$ \\
\hline \multicolumn{7}{|l|}{ Marital status } \\
\hline Never married & 1.00 & - & 1.00 & - & 1.00 & - \\
\hline Married & 0.98 & $0.60-1.60$ & 1.00 & $0.60-1.68$ & 0.90 & $0.42-1.93$ \\
\hline Separated/widowed/divorced & 0.71 & $0.49-1.04$ & 0.71 & $0.48-1.06$ & 0.92 & $0.50-1.69$ \\
\hline \multicolumn{7}{|l|}{ Injector status } \\
\hline Never & 1.00 & - & 1.00 & - & 1.00 & - \\
\hline Former & 0.65 & $0.35-1.20$ & 0.80 & $0.42-1.53$ & 0.60 & $0.16-2.22$ \\
\hline Current & 0.50 & $0.29-0.87$ & 0.69 & $0.38-1.25$ & 0.72 & $0.21-2.50$ \\
\hline \multicolumn{7}{|l|}{ Ever in methadone treatment } \\
\hline No & 1.00 & - & 1.00 & - & 1.00 & - \\
\hline Yes & 0.78 & $0.56-1.09$ & 0.74 & $0.50-1.11$ & 0.58 & $0.31-1.09$ \\
\hline \multicolumn{7}{|l|}{ Characteristics of witnessed overdose events } \\
\hline \multicolumn{7}{|l|}{ Location of witnessed overdose } \\
\hline Home & 1.00 & - & 1.00 & - & 1.00 & - \\
\hline Shooting gallery & 0.88 & $0.56-1.38$ & 0.93 & $0.58-1.50$ & 0.75 & $0.37-1.53$ \\
\hline Abandoned building/SRO/hotel room & 0.74 & $0.39-1.37$ & 0.79 & $0.41-1.51$ & 0.52 & $0.21-1.32$ \\
\hline Public place ${ }^{\mathrm{b}}$ & 2.19 & $1.38-3.49$ & 2.20 & $1.35-3.58$ & 1.31 & $0.64-2.68$ \\
\hline Other ${ }^{\mathrm{c}}$ & 1.19 & $0.70-2.03$ & 1.19 & $0.68-2.07$ & 1.00 & $0.44-2.29$ \\
\hline \multicolumn{7}{|l|}{ Overdose experience of witnesses } \\
\hline \multicolumn{7}{|l|}{ Number of overdoses witnessed in lifetime } \\
\hline $1-2$ & 1.00 & - & 1.00 & - & 1.00 & - \\
\hline $3-5$ & 0.88 & $0.55-1.41$ & 1.06 & $0.65-1.73$ & 1.67 & $0.78-3.58$ \\
\hline $6-10$ & 0.73 & $0.45-1.18$ & 0.74 & $0.44-1.23$ & 1.06 & $0.48-2.30$ \\
\hline $11+$ & 0.59 & $0.38-0.94$ & 0.68 & $0.42-1.11$ & 0.78 & $0.37-1.64$ \\
\hline \multicolumn{7}{|l|}{ Ever overdosed } \\
\hline No & 1.00 & - & 1.00 & - & & \\
\hline Yes & 0.48 & $0.35-0.68$ & 0.56 & $0.39-0.80$ & & \\
\hline \multicolumn{7}{|l|}{ Someone called 911 at own last overdose } \\
\hline No & 1.00 & - & & & 1.00 & - \\
\hline Yes & 3.02 & $1.86-4.91$ & & & 1.26 & $0.57-2.75$ \\
\hline \multicolumn{7}{|l|}{ Taken to hospital at own last overdose } \\
\hline No & 1.00 & - & & & 1.00 & - \\
\hline Yes & 3.68 & $2.26-6.00$ & & & 3.18 & $1.44-6.99$ \\
\hline
\end{tabular}

${ }^{a}$ Model includes all witnesses to overdose who had ever overdosed themselves and who had non-missing values for all covariates $(N=291)$.

${ }^{\mathrm{b}}$ Public place includes street, schoolyard, parking lot or other open area, bar, restaurant, store or other public building.

c Other location includes car, jail, or "other".

$\dagger$ Model includes all respondents who had ever witnessed an overdose and who had non-missing values for all covariates $(N=652)$.

involving heroin. About one third of witnesses to heroinrelated overdose did not get medical help for the victim during the last witnessed overdose event, citing fear of police response as the most common concern. The respondent never having had an overdose her/himself and the witnessed overdose occurring in a public place were associated with the likelihood of calling for medical help during the last witnessed overdose. Only a small proportion of respondents engaged in first aid attempts, while physical stimulation attempts were common.
The high proportion of respondents in this study who had ever witnessed a heroin-related overdose is consistent with findings in several other studies (Darke and Hall, 2003; Davidson et al., 2002; Darke et al., 1996b; Strang et al., 1999), suggesting that habitual drug users will likely be confronted with the opportunity to help an overdose victim at some point in their drug using career. The prevalence of calling for medical help in this study was also comparable, if slightly higher, than that reported in other locations (Davidson et al., 2002; 
Table 3

Actions taken at last heroin-related witnessed overdose

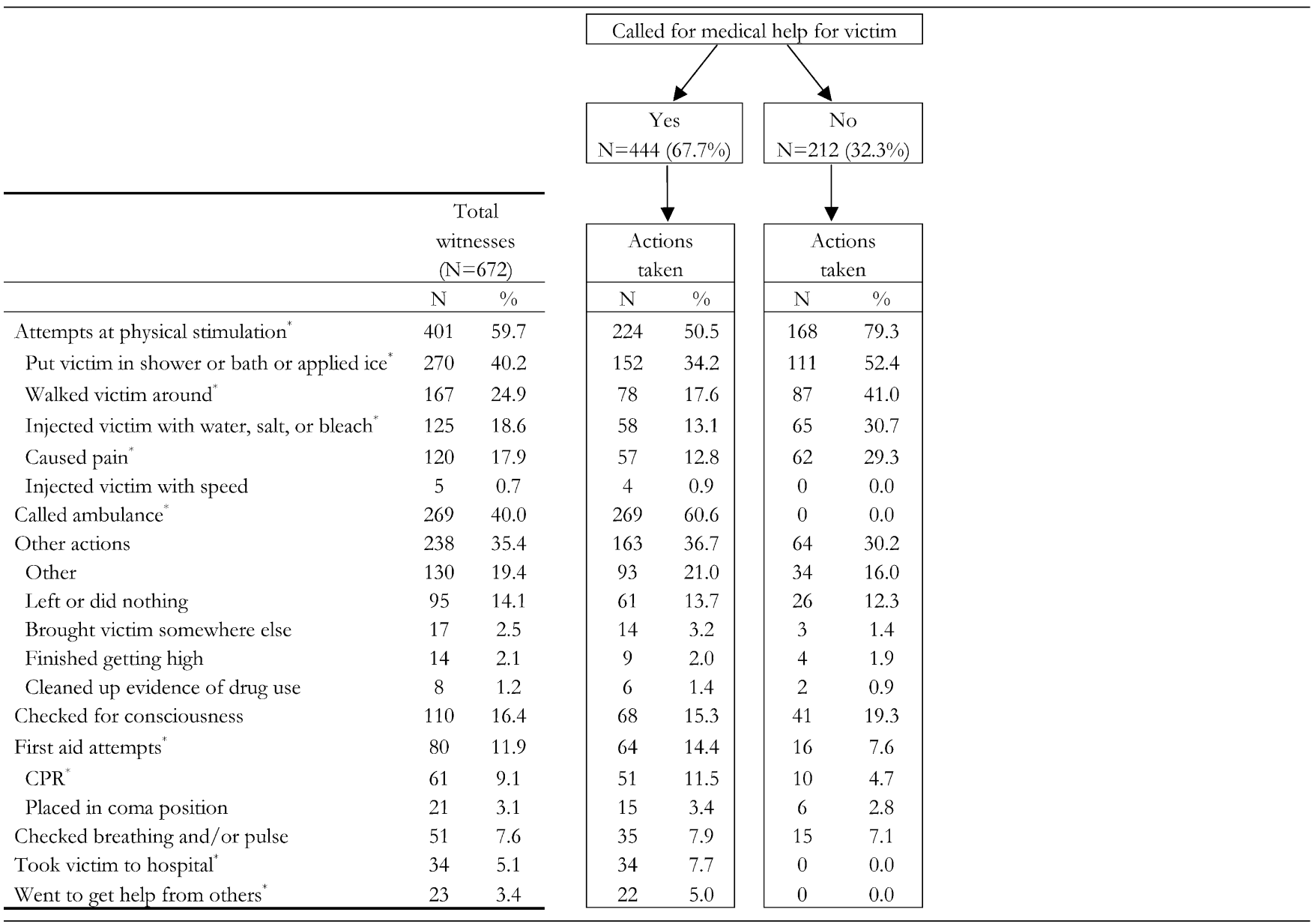

*Two-tailed $\chi^{2} p$-value $<0.05$ for relation between calling for medical help for the overdose victim and each of the possible actions taken.

McGregor et al., 1998; Darke et al., 1996b; Bennett and Higgins, 1999).

Witnesses to overdose events occurring in public areas like bars, restaurants, and on the street were more likely to get medical help for the overdose victim than witnesses to overdoses occurring in residential settings. A larger percentage of witnesses to overdoses occurring in public locations reported being of no relation to the overdose victim; it may be possible that unconnected bystanders and even family members and friends may be more likely to call for help in public situations, as such situations afford greater anonymity and, consequently, less fear of personal trouble arising from potential police response. However, research in the United States and elsewhere has indicated that the majority of fatal overdoses occur in private locations like homes and hotels (CDC, 2000a; Davidson et al., 2003; Sporer, 2003), as concerns about police surveillance often prompt drug users to engage in drug-related activities in less visible areas (Dovey et al., 2001; Burris et al., 2004); accordingly, harm reduction efforts need to work to improve responses to overdoses occurring in private locations.
Respondents with a personal history of overdose were less likely to seek outside help during the last witnessed overdose than those lacking such experience. This may reflect a belief on the part of witnesses who have overdosed themselves that they are equipped to handle the situation without aid, having experienced a similar incident personally. Since greater frequency of alcohol use and drug injection is associated with prior overdose experience (Seal et al., 2001; Bennett and Higgins, 1999; Powis et al., 1999; McGregor et al., 1998; Darke et al., 1996a), it is also possible that respondents with a history of overdose were more likely to be intoxicated when they witnessed an overdose, hence having impaired judgment and being less likely to call for medical help. However, respondents who had been taken to the hospital during their own most recent overdose were more likely to call for outside help than those who had not received such medical attention. It is possible that uncertainties and fears about medical care and potential police involvement at overdose events, which commonly dissuade drug users from seeking help (Sergeev et al., 2003; Davidson et al., 2002), were less acute among those who had already experienced an overdose and subsequent hospitalization themselves. 
Table 4

Reasons for delaying before calling or not calling for medical help at last heroin-related witnessed overdose

\begin{tabular}{|c|c|c|c|c|c|c|}
\hline & & & & & elp & \\
\hline & & & & & & \\
\hline & & & & & & \\
\hline & & & & $\mathrm{N}=4$ & & $2.3 \%)$ \\
\hline & & & call & $\begin{array}{l}\text { d } \\
\text { help }\end{array}$ & & \\
\hline & Wit & esses & & & & \\
\hline & $\begin{array}{l}\text { who } \\
\text { or } \mathrm{d}\end{array}$ & $\begin{array}{l}\text { layed } \\
\text { not }\end{array}$ & & $.2 \%)$ & & \\
\hline & get & & & & & \\
\hline & & & Reas & delay & & \\
\hline & $\mathrm{N}$ & $\%$ & $\mathrm{~N}$ & $\%$ & $\mathrm{~N}$ & $\%$ \\
\hline Police response & 157 & 52.2 & 59 & 66.3 & 98 & 46.2 \\
\hline Fear of police involvement & 144 & 47.8 & 55 & 61.8 & 89 & 42.0 \\
\hline Fear of manslaughter charges & 31 & 10.3 & 12 & 13.5 & 19 & 9.0 \\
\hline Outstanding warrants among those present & 8 & 2.7 & 4 & 4.5 & 4 & 1.9 \\
\hline Thought could take care of it without help & 91 & 30.2 & 14 & 15.7 & 77 & 36.3 \\
\hline Other & 64 & 21.3 & 19 & 21.4 & 45 & 21.2 \\
\hline Drug use interference & 31 & 10.3 & 10 & 11.2 & 21 & 9.9 \\
\hline Out of it & 14 & 4.7 & 4 & 4.5 & 10 & 4.7 \\
\hline Wanted to finish getting high & 17 & 5.7 & 6 & 6.7 & 11 & 5.2 \\
\hline Didn't know what to do & 17 & 5.7 & 2 & 2.3 & 15 & 7.1 \\
\hline Worried about victim's reaction & 12 & 4.0 & 1 & 1.1 & 11 & 5.2 \\
\hline No phone or phone not working & 12 & 4.0 & 5 & 5.6 & 7 & 3.3 \\
\hline Worried about loss of confidentiality & 11 & 3.7 & 5 & 5.6 & 6 & 2.8 \\
\hline Negative attitudes of medical staff & 2 & 0.7 & 1 & 1.1 & 1 & 0.5 \\
\hline Person clearly already dead & 0 & 0.0 & 0 & 0.0 & 0 & 0.0 \\
\hline Cost of ambulance & 0 & 0.0 & 0 & 0.0 & 0 & 0.0 \\
\hline
\end{tabular}

Attempts to revive overdose victims through physical stimulation (e.g., applying ice, causing pain) were commonly reported among witnesses, as has been documented in other studies (Davidson et al., 2002; Bennett and Higgins, 1999). A greater percentage of respondents in this study (19.3\%) engaged in the ineffective practice of injecting the overdose victim with water, salt, bleach, or speed than has been previously reported by young injection drug users in San Francisco (2\%; Davidson et al., 2002), while a smaller percentage (11.9\%) employed first aid measures than has been reported by witnesses to overdose in San Francisco (57.0\%; Davidson et al., 2002), Australia (39.0\%; McGregor et al., 1998), and the United Kingdom (45.0\%; Bennett and Higgins, 1999). These discrepancies may be attributed to differential knowledge of and experience in overdose prevention and treatment among drug using populations in different locations. The high prevalence of ineffective methods in treating witnessed overdoses suggests that more education in appropriate overdose management is needed among drug users, including training in first aid, especially in light of research indicating that bystander CPR performed prior to the arrival of emergency medical services improves outcomes for overdose victims (Dietze et al., 2002).

Mortality as a result of heroin overdose was significantly less likely during overdose events in which witnesses thought they were capable of taking care of the overdose victim without aid. This finding may indicate that drug users who have been adequately trained in overdose management techniques and who feel confident in their abilities to practice those techniques may be effective in preventing overdose mortality, providing further evidence in favor of increased efforts to train drug users in first aid and other skills. However, these results should be interpreted with caution in light of the small sample from which they were derived.

Fear of police response, including concerns over outstanding warrants and potential manslaughter charges, dominated the reasons reported by witnesses for not getting or delaying before getting help for the overdose victim, as has been reported elsewhere (McGregor et al., 1998; Darke et al., 1996b). Police attendance at overdose events has varied from 13-16\% of nonfatal overdoses in Australia (Dietze et al., 2003; Clark and Bates, 2003) to $95 \%$ of fatal overdoses in San Francisco (Davidson et al., 2003), with 5\% of witnesses to overdoses in San Francisco reporting having been arrested at least once while present at an overdose event (Davidson et al., 2002). While we do not have comparable data for overdose events occurring in NYC, it seems clear that drug users perceive a high risk of arrest associated with calling for emergency medical services after an overdose in NYC. 
There were a number of limitations to this study. We do not know if the respondent or someone else present performed the actions reported at the last witnessed overdose, reducing our power to detect associations between characteristics of the witness and the likelihood of calling for medical help during observed overdose events. Additionally, the cross-sectional nature of the study presents some difficulties in assessing the time frame of the respondent's own overdose experience in relation to the witnessed overdose event. Since all information presented here was obtained via self-report, it is possible that respondents did not have complete information about the results of the overdoses they witnessed or were not fully aware of the actions taken at their own most recent overdose because of impaired consciousness at the time. Furthermore, the variation in amount of time elapsed between the last witnessed overdose and the interview may have led to differential memory and reporting of actions and outcomes. In addition, our ability to compare the responses to witnessed overdose across drug users of different races/ethnicities was limited by our predominantly minority sample, and thus relatively small comparison group of white drug users. Finally, since participants were drawn from select neighborhoods in NYC with high proportions of minority populations, results may not be generalizable to other populations or cities.

Despite these limitations, our findings lend further support to the notion that drug users are frequently confronted with opportunities to reduce morbidity and mortality from overdose in their peers, but often do not act effectively. Drug users should be encouraged to activate the emergency medical system immediately when witnessing an overdose and police involvement at the scene of drug overdoses should be reduced. Injection drug users have expressed a willingness to participate in programs providing training in CPR as well as take-home naloxone and instruction in its use (Seal et al., 2003); such interventions may be particularly effective among members of large injection drug networks (Latkin et al., 2004) and should be considered in NYC. Harm reduction activities that provide education about overdose prevention and equip drug users to manage overdoses successfully once they occur, as well as efforts to improve social and structural conditions that contribute to increased risk for overdose among drug users (e.g., homelessness and income distribution), can make a substantial difference in overdose frequency and outcomes (Darke and Hall, 2003; McGregor et al., 1998; Strang et al., 1999; Fischer et al., 2004; Galea et al., 2003b). The circumstances of witnessed overdoses should be further described in other populations and cities to more fully assess differences in responses that may be associated with differential morbidity and mortality by race/ethnicity.

\section{Acknowledgements}

This work was funded by grants DA-06534, DA-12801S1, and R01-DA-017642-01 from the National Institutes of Health.

\section{References}

Bennett, G.A., Higgins, D.S., 1999. Accidental overdose among injecting drug users in Dorset, UK. Addiction 94, 1179-1190.

Burris, S., Blankenship, K.M., Donoghoe, M., Sherman, S., Vernick, J.S., Case, P., Lazzarini, Z., Koester, S., 2004. Addressing the "risk environment" for injection drug users: the mysterious case of the missing cop. Milbank Q. 82, 125-156

Centers for Disease Control and Prevention (CDC), 2000a. Heroin overdose deaths-Multnomah County, Oregon, 1993-1999. MMWR Morb. Mortal. Wkly. Rep. 49, 633-636.

Centers for Disease Control and Prevention (CDC), 2000b. Unintentional opiate overdose deaths-King County, Washington, 1990-1999. MMWR Morb. Mortal. Wkly. Rep. 49, 636-640.

Centers for Disease Control and Prevention (CDC), 2004. Unintentional and undetermined poisoning deaths-11 states, 1990-2001. MMWR Morb. Mortal. Wkly. Rep. 53, 233-238.

Clark, M.J., Bates, A.C., 2003. Nonfatal heroin overdoses in Queensland, Australia: an analysis of ambulance data. J. Urban Health 80 , 238-247.

Darke, S., Hall, W., 2003. Heroin overdose: research and evidence-based intervention. J. Urban Health 80, 189-200.

Darke, S., Ross, J., Hall, W., 1996a. Overdose among heroin users in Sydney, Australia: I. Prevalence and correlates of non-fatal overdose. Addiction 91, 405-411.

Darke, S., Ross, J., Hall, W., 1996b. Overdose among heroin users in Sydney, Australia: II. Responses to overdose. Addiction 91, 413417.

Darke, S., Sims, J., McDonald, S., Wickes, W., 2000. Cognitive impairment among methadone maintenance patients. Addiction 95, 687-695.

Darke, S., Zador, D., 1996. Fatal heroin overdose: a review. Addiction 91, 1765-1772.

Davidson, P.J., McLean, R.L., Kral, A.H., Gleghorn, A.A., Edlin, B.R., Moss, A.R., 2003. Fatal heroin-related overdose in San Francisco, 1997-2000: a case for targeted intervention. J. Urban Health 80, 261-273.

Davidson, P.J., Ochoa, K.C., Hahn, J.A., Evans, J.L., Moss, A.R., 2002. Witnessing heroin-related overdoses: the experiences of young injectors in San Francisco. Addiction 97, 1511-1516.

Diaz, T., Des Jarlais, D.C., Vlahov, D., Perlis, T.E., Edwards, V., Friedman, S.R., Rockwell, R., Hoover, D., Williams, I.T., Monterroso, E.R., 2001a. Factors associated with prevalent hepatitis C: differences among young adult injection drug users in lower and upper Manhattan, New York City. Am. J. Public Health 91, 23-30.

Diaz, T., Vlahov, D., Greenberg, B., Cuevas, Y., Garfein, R., 2001b. Sexual orientation and HIV infection prevalence among young Latino injection drug users in Harlem. J. Womens Health Gend. Based Med. 10, 371-380.

Dietze, P., Cantwell, K., Burgess, S., 2002. Bystander resuscitation attempts at heroin overdose: does it improve outcomes? Drug Alcohol Depend. 67, 213-218.

Dietze, P., Jolley, D., Cvetkovski, S., 2003. Patterns and characteristics of ambulance attendance at heroin overdose at a local-area level in Melbourne, Australia: implications for service provision. J. Urban Health 80, 248-260

Dovey, K., Fitzgerald, J., Choi, Y., 2001. Safety becomes danger: dilemmas of drug-use in public space. Health Place 7, 319-331.

Fischer, B., Brissette, S., Brochu, S., Bruneau, J., el-Guebaly, N., Noël, L., Rehm, J., Tyndall, M., Wild, C., Mun, P., Haydon, E., Baliunas, D., 2004. Determinants of overdose incidents among illicit opioid users in 5 Canadian cities. Can. Med. Assoc. J. 171, 235-239.

Galea, S., Ahern, J., Tardiff, K., Leon, A.C., Coffin, P.O., Derr, K., Vlahov, D., 2003a. Racial/ethnic disparities in overdose mortality trends in New York City, 1990-1998. J. Urban Health 80, 201-211.

Galea, S., Ahern, J., Vlahov, D., Coffin, P.O., Fuller, C., Leon, A.C., Tardiff, K., 2003b. Income distribution and risk of fatal drug overdose in New York City neighborhoods. Drug Alcohol Depend. 70, 139-148. 
Galea, S., Vlahov, D., 2002. Social determinants and the health of drug users: socioeconomic status, homelessness, and incarceration. Public Health Rep. 117 (Suppl. 1), S135-S145.

Karpati, A., Lu, X., Mostashari, F., Thorpe, L., Frieden, T.R., 2003a. The health of Central Bronx. NYC Community Health Profiles 1 (19), 1-12, Accessed on 23 August 2004, http://www.nyc.gov/html/doh/ pdf/data/2003nhp-bronxd.pdf.

Karpati, A., Lu, X., Mostashari, F., Thorpe, L., Frieden, T.R., 2003b. The health of Central Bronx. NYC Community Health Profiles 1 (40), 1-12, Accessed on 23 August 2004, http://www.nyc.gov/html/doh/pdf/ data/2003nhp-bronxa.pdf.

Latkin, C.A., Hua, W., Tobin, K., 2004. Social network correlates of self-reported non-fatal overdose. Drug Alcohol Depend. 73, 61-67.

McGregor, C., Darke, S., Ali, R., Christie, P., 1998. Experience of nonfatal overdose among heroin users in Adelaide, Australia: circumstances and risk perceptions. Addiction 93, 701-711.

New York City Department of Health and Mental Hygiene (NYC DOHMH), 2003. Summary of vital statistics 2002: the City of New York Office of Vital Statistics, New York. Accessed on 23 August 2004, http://www.nyc.gov/html/doh/pdf/vs/2002sum.pdf.

Ochoa, K.C., Hahn, J.A., Seal, K.H., Moss, A.R., 2001. Overdosing among young injection drug users in San Francisco. Addict. Behav. $26,453-460$.

Ompad, D., Galea, S., Fuller, C.M., Edwards, V., Vlahov, D., in press. Ecstasy use among Hispanic and Black substance users in New York City. Subst. Use Misuse.

Powis, B., Strang, J., Griffiths, J., Taylor, C., Williamson, S., Fountain, J., Gossop, M., 1999. Self-reported overdose among injecting drug users in London: extent and nature of the problem. Addiction 94, 471-478.
Seal, K.H., Downing, M., Kral, A.H., Singleton-Banks, S., Hammond, J., Lorvick, J., Ciccarone, D., Edlin, B.R., 2003. Attitudes about prescribing take-home naloxone to injection drug users for the management of heroin overdose: a survey of street-recruited injectors in the San Francisco Bay Area. J. Urban Health 80, 291-301.

Seal, K.H., Kral, A.H., Gee, L., Moore, L.D., Bluthenthal, R.N., Lorvick, J., Edlin, B., 2001. Predictors and prevention of nonfatal overdose among street-recruited injection heroin users in the San Francisco Bay Area, 1998-1999. Am. J. Public Health 91, 1842-1846.

Sergeev, B., Karpets, A., Sarang, A., Tikhonov, M., 2003. Prevalence and circumstances of opiate overdose among injection drug users in the Russian Federation. J. Urban Health 80, 212-219.

Sporer, K.A., 1999. Acute heroin overdose. Ann. Int. Med. 130, 584-590.

Sporer, K.A., 2003. Strategies for preventing heroin overdose. Br. Med. J. $326,442-444$.

Sporer, K.A., Firestone, J., Isaacs, S.M., 1996. Out-of-hospital treatment of opioid overdoses in an urban setting. Acad. Emerg. Med. 3, 660-667.

Strang, J., Powis, B., Best, D., Vingoe, L., Griffiths, P., Taylor, C., Welch, S., Gossop, M., 1999. Preventing opiate overdose fatalities with takehome naloxone: pre-launch study of possible impact and acceptability. Addiction 94, 199-204.

Warner-Smith, M., Darke, S., Lynskey, M., Hall, W., 2001. Heroin overdose: causes and consequences. Addiction 96, 1113-1125.

Warner-Smith, M., Darke, S., Day, C., 2002. Morbidity associated with non-fatal heroin overdose. Addiction 97, 963-967.

Zador, D., Sunjic, S., Darke, S., 1996. Heroin-related deaths in New South Wales, 1992: toxicological findings and circumstances. Med. J. Aust. 164, 204. 